\title{
Flexibilización probatoria y equidad: propuestas para la justicia del posconflicto*
}

\section{Evidential flexibility and fairness: Proposals for post-conflict justice}

\author{
Juan Felipe Sánchez Gutiérrez ${ }^{* *}$ \\ Michael Julián Córdoba Hernández ${ }^{* * *}$ \\ Hannier Santiago Serrano Manrique ${ }^{* * *}$ \\ Adriana Carolina Castro Bermúdez ${ }^{* * * *}$
}

Fecha de recepción: 8 de julio de 2018

Fecha de aprobación: 11 de noviembre de 2018

* El presente artículo es producto de la línea de Estudios en Derecho Constitucional del semillero Reformas Constitucionales Derivadas del Acuerdo para la Superación del Conflicto Armado Interno entre el Estado y las Fuerzas Armadas Revolucionarias Farc-EP, gestionado por la Institución Universitaria Politécnico Grancolombiano Sede Bogotá, para el XVIII Concurso Internacional para Estudiantes de Derecho Nivel Pregrado, organizado por el Instituto Colombiano de Derecho Procesal en el marco del XXXVIII Congreso Colombiano de Derecho Procesal. Citar como Sánchez Gutiérrez, J., Córdoba Hernández, M., Serrano Manrique, H. y Castro Bermúdez, A. (2019). Flexibilización probatoria y equidad: propuestas para la justicia del posconflicto. Via Inveniendi et Iudicandi, 14(1), 157-190. Doi: https://doi.org/10.15332/ s1909-0528.2019.0001.06

** Estudiante de Derecho de la Institución Universitaria Politécnico Grancolombiano (Bogotá, Colombia). Miembro fundador del referido semillero. jfsanchezgu@poligran.edu.co

*** Estudiante de Derecho de la Institución Universitaria Politécnico Grancolombiano (Bogotá, Colombia). Miembro fundador del referido semillero.mjcordoba@poligran.edu.co

**** Estudiante de Derecho de la Institución Universitaria Politécnico Grancolombiano (Bogotá, Colombia). Miembro del referido semillero desde 2017. hsserrano@poligran.edu.co

***** Abogada de la Universidad Santo Tomás de Aquino. Especialista en Derecho Administrativo de la misma universidad. Especialista en Derecho Constitucional de la Universidad de Salamanca. Especialista en Contratación Estatal de la Universidad Externado de Colombia. Candidata a magíster en Derecho Público de la Universität Konstanz, en convenio con la Universidad Santo Tomás de Aquino. Directora del Consultorio Jurídico y de la Especialización en Contratación Estatal y Negocios Jurídicos de la Administración de la Institución Universitaria Politécnico Gran Colombiano y docente de esa misma universidad y de la Universidad Militar Nueva Granada. Tutora y directora del referido semillero. accastrobe@poligran.edu.co 


\section{RESUMEN}

La Corte Interamericana de Derechos Humanos, siguiendo directrices de ius cogens y derecho blando en materia de derechos de las víctimas, ha creado reglas de flexibilización probatoria para garantizar la tutela jurisdiccional efectiva de las víctimas de violaciones graves a los derechos más esenciales. Aprovechando este escenario, en Colombia, en virtud del diseño jurídico-procesal que se ha creado con ocasión del conflicto armado, se han adoptado de manera insuficiente prácticas usadas en el SIDH en materia de flexibilización probatoria y uso de la equidad. Las herramientas que operan disposiciones correspondientes a DIDH y $\mathrm{DIH}$, cuando se adopten de manera más íntegra, brindarán mayores garantías a las víctimas y serán de gran ayuda práctica y hermenéutica para los jueces de dańos al momento de fundar sus decisiones sobre los incidentes de reparación integral y los procesos de reparación directa que versen sobre graves violaciones a los derechos humanos.

Palabras clave: derechos humanos y de las víctimas, flexibilización probatoria, análisis del contexto, control de convencionalidad.

\section{Abstract}

The Inter-American Court of Human Rights, following guidelines of ius cogens and soft law in relation with the victim's rights, has created rules of probative flexibilization to guarantee the effective jurisdictional tutelage to the victims of serious human rights violations. Thanks to this scenario, in Colombia, due of the legal-procedural design that has been created in virtue of the armed conflict, practices used in the ISHR have been insufficiently adopted in terms of probative flexibilization and the use of equity. The tools provided conforming to IHRL and IHL, when it will be adopted in a more comprehensive way, will provide more guarantees for victims, and will be a great practical and hermeneutical assistance to the damage judge to base their decisions for integral reparation incidents and direct reparation processes when they were related with serious violations of human rights.

Keywords: Human and victim's rights, probative flexibilization, equity, context analysis, conventionality control. 


\title{
INTRODUCCIÓN
}

\section{Lo contramayoritario no es sinónimo de antidemocrático}

\begin{abstract}
A lo largo de este artículo, y gracias a la pertinencia de las discusiones académicas relacionadas con los derechos de las víctimas, se indagará sobre la importancia de aplicar métodos de flexibilización probatoria más allá del contexto de los procesos de justicia transicional (Jurisdicción Especial para la Paz, JEP) y la jurisdicción de lo contencioso administrativo (JCA), fundamentando su uso en las fuentes del derecho. En este caso, la fuente será la equidad como piedra angular de la reparación de las víctimas de violaciones a los derechos humanos de manera subsidiaria cuando se encuentren en dificultades probatorias. Producto de esta necesidad nace también la importancia de determinar si es jurídicamente viable hacer uso de la flexibilización probatoria fuera de procesos de la JEP y la JCA, en casos límite relacionados con el conflicto armado interno y para otorgar reparaciones en equidad.
\end{abstract}

Además, se promoverá el uso del análisis del contexto como medio de prueba, no solo para determinar el quantum punitivo dentro de procesos de justicia transicional, sino para adoptar los criterios en materia de reparación ${ }^{1}$ usados por la Corte IDH para hacerlos extensivos a la JCA y ante el juez penal de dańos, a sabiendas de la clara obligación de garantes de convencionalidad de las autoridades judiciales internas. Este contexto no es más que un marco de referencia contentivo de aspectos esenciales de elementos de orden político, económico, cultural, histórico y social, en el cual se

1 En concordancia con lo dispuesto en líneas anteriores, aunque no es el fondo del presente manuscrito, es importante analizar cuál es la naturaleza jurídica de la reparación integral de las víctimas por desplazamiento forzado, lo cual supone un análisis cualitativo con una orientación hacia la esencia de la reparación integral que se pretende dar a las víctimas del conflicto armado y los aportes que de su práctica se pueden obtener. Ello debe incluir tanto los aportes en el área jurídica, con los pronunciamientos jurisprudenciales expedidos en el espacio interno por los organismos colombianos y las contribuciones que se realizan en el marco del derecho internacional, como los aportes en el campo político (Moreno y Álvarez, 2017).

$\mathrm{Al}$ respecto, conviene no olvidar que "bajo el mandato constitucional consagrado en el artículo 90 de nuestra Carta Política, Colombia se ha constituido como un Estado garantista de los derechos de sus administrados en materia de responsabilidad, indicándose que el Estado es responsable de los daños que ocasione a los particulares no solo por sus acciones sino también por sus omisiones” (Castro, 2018, p. 170). 
han cometido delitos por parte de grupos criminales identificables, gracias a su modus operandi, como actores macrocriminales.

Por eso, en este artículo se hará referencia constantemente al concepto de la flexibilización probatoria, que implica la adopción de singularidades útiles para minimizar las formalidades que regulan la actividad probatoria dentro del proceso judicial. Los postulados de flexibilización probatoria se han usado tradicionalmente en casos relacionados con violaciones graves a los derechos humanos. Sin embargo, con la modernización de la teoría general del proceso, es habitual encontrar instituciones como el juramento estimatorio dentro del proceso civil ordinario.

Gracias a las tesis de la Corte IDH instituidas en sus múltiples providencias se ha venido implementando el análisis del contexto como una herramienta de flexibilización probatoria para conceder reparaciones en equidad a quienes, siendo víctimas de violaciones a los derechos humanos, no logren acreditar alguno de los elementos de la responsabilidad sobre todo en el marco de la justicia interamericana ${ }^{2}$.

En un contexto como el colombiano, y al entender que un elemento transversal de todos los conflictos armados es la producción sistemática de víctimas, es evidente que para estas resulta difícil conseguir y aportar elementos materiales que acrediten, por ejemplo, la existencia del nexo causal entre un hecho presuntamente dañoso y el daño del cual son sujeto pasivo ${ }^{3}$.

Así, no es solamente necesario sino perentorio adoptar de pleno las reglas de flexibilización probatoria para reparar a las víctimas que por su condición de subordinación, no tienen herramientas suficientes para acreditar los deberes que el

2 Al respecto, es importante resaltar que "el Sistema Interamericano de Derechos Humanos sufre en la actualidad una grave crisis financiera. Ello en el plano de la protección de los derechos humanos, puede generar consecuencias de gravedad, ya que [aquel] podría quedar sin la capacidad para poder cumplir con sus funciones" (Murcia, 2018, p. 55).

$3 \mathrm{Al}$ respecto, "es así como en el Estado colombiano se crea el marco jurídico para la paz, el cual se plantea con la finalidad de abrir un espacio constitucional para el desarrollo de una estrategia integral coherente de justicia transicional que permita la máxima satisfacción posible de los derechos de las víctimas y la transición hacia una paz estable y duradera" (Yani, 2017, p. 38). 
principio del onus probandi supone, especialmente en los procesos de reparación directa y los incidentes de reparación integral en el asunto penal.

Con este artículo se pretende crear un escenario idóneo para discutir la necesidad de importar de lleno los postulados en materia de reparación y equidad del SIDH cuando la causa material de una relación jurídico-procesal revista las cualidades para poder considerarla violatoria de los elementos fundantes del ius cogens y la prevalencia de la carga procesal de probar un daño pueda traducirse en contravenciones irremediables a los derechos humanos y fundamentales de las víctimas del conflicto armado ${ }^{4}$.

Es claro que el análisis del contexto como una modalidad de flexibilización probatoria no puede suponer una prerrogativa absoluta e irresponsable en favor de cualquiera de las partes dentro del proceso judicial. Por eso, la manera más adecuada de brindar balance a las armas de la litis reside en la implementación de las herramientas ampliamente usadas en el SIDH, la equidad, y las reglas de la lógica y la experiencia.

\section{LA EQUIDAD COMO CRITERIO INTEGRADOR DEL DERECHO}

La universalidad o plenitud resulta para el derecho una condición esencial. Con esta premisa la construcción de la norma jurídica se hace bajo la creencia de que no existe precepto que no haya sido normado por el derecho. Esta idea conduce a negar la existencia de lagunas en el derecho o antinomias jurídicas.

Pero todo ordenamiento jurídico contiene incoherencias en su regulación normativa. Para llenar estos vacíos nacen los procedimientos de integración normativa, que en

4 De conformidad con Joya y Sánchez "se denota que Colombia ha estado inmersa en dos etapas especiales de transición que han sido de suma importancia para la historia del país, la primera fue en el año 2012, y la segunda la estamos viviendo en la actualidad, a pesar [de] que durante este contexto se observan varias falencias jurídicas, como lo son las limitantes que se establecen frente al poder constituyente para que ningún ciudadano en ejercicio de la acción pública de inconstitucionalidad pueda ejercer la salvaguarda de la Constitución; también es cierto que estamos de acuerdo con el perdón, la reparación, reconciliación y no repetición de los actos violentos que han desangrado nuestra sociedad, sin embargo, enfatizando que queremos que no se nos desconozcan los principios democráticos por los que hemos luchado por más de cincuenta años, y los cuales se hicieron verídicos a partir de la Carta Política del año 91” (2018, p. 220). 
nuestra legislación están consagrados en la Ley 153 de 1887, especialmente en sus artículos 8 y 13, además del artículo 230 de la Constitución Política 5 .

La equidad es también un criterio integrador. Ya Aristóteles, en su Ética nicomáquea, determina que es un instrumento que "sirve para rectificar o ablandar la ley, si fuera necesario". Es menester recordar que el derecho positivo está construido bajo la égida de preceptos de carácter abstracto. Así las cosas, la norma no debe contemplar las vicisitudes propias de cada caso particular, sino que se elabora en virtud de las situaciones que tienen mayor frecuencia, lo cual implica que está construida de forma universal y fija.

En virtud del principio de plenitud hermenéutica las lagunas en la interpretación de la ley no son lógicas sino axiológicas, lo que significa que la labor integradora del juez está para ser invocada cuando se presente un conflicto de valores dentro del ordenamiento jurídico. Si se relaciona esto con el concepto de equidad, la labor correctiva de esta deviene en la adopción de una decisión excepcional y especialísima, divergente de la normativa general, pues en una situación que por sus características resulta fuera del objeto de dicha norma su aplicación supondría un tratamiento injusto.

Entonces, la aplicación del criterio de equidad tiene la virtualidad de conminar al juez a valorar las circunstancias excepcionales del caso que lleva y adaptarse a ellas para salvaguardar el principio de igualdad en que la norma se inspira y lograr que los derechos sean efectivos, pues en su función correctiva la equidad pretende subsanar las falencias generadas por la aplicación del igualitarismo.

En materia de reparación, generalmente en relación con violaciones graves a los derechos humanos, la equidad supone un criterio que le permite al juez, apoyado en la experiencia y la lógica, decretar la medida que le pueda ser más favorable a la

5 Es importante no olvidar que "en Colombia la Constitución Política de 1991 viene a ser un punto de quiebre, pues a partir de allí se pasó de un Estado legislativo a uno de constitucionalidad, en el que la Carta Superior, además de ser un pacto social, se erigió como una verdadera norma jurídica susceptible de aplicación directa” (Revelo y Valbuena, 2017, p. 63). 
víctima conforme al caso en particular — en el sentido de darle a cada quién lo que le pertenece- - Por ello, la equidad en este sentido supone la humanización del caso concreto (Fundación Tomás Moro, 1991); devolverle a cada quién lo que se le ha arrebatado sin acudir a reglas positivas.

\section{FLEXIBILIZACIÓN PROBATORIA}

Entre los mayores vicios de la jurisdicción se cuenta caer en una desviación de su propósito, en el sentido de que el objetivo del proceso, más allá de ser un método de cognición del juez, es procurar la garantía de la efectividad de los derechos, y por ende, la solución pacífica de los conflictos.

Cuando no se entiende ese concepto, la causa final del proceso se contamina por la burocratización, so pretexto de la garantía de un bien jurídico superior. Esto hace de la disciplina una mera técnica que convierte al usuario de la justicia en un simple eslabón de una cadena; que olvida al ser humano necesitado de la materialización del poder legítimo del Estado para la protección de su derecho y la institucionalización de su conflicto.

La flexibilización probatoria implica la adopción de singularidades que derivan en la minimización de las formalidades que regulan la actividad probatoria dentro del proceso judicial. Se admite cuando los hechos que dan vida al proceso revisten una gravedad tal que ponen a la víctima en una situación de desventaja al reclamar la protección jurisdiccional de sus derechos.

La necesidad de flexibilizar los estándares probatorios en casos de grave desconocimiento de los derechos humanos y del derecho internacional humanitario se funda en el hecho del rompimiento del canon procesal, en virtud del cual las partes acceden al proceso en igualdad de condiciones, pues en estos eventos las víctimas quedan en una relación diametralmente asimétrica de cara a la prueba.

Ahora bien, la flexibilización probatoria parte del principio de la libertad probatoria, que trataremos de manera detallada a continuación. 


\section{De las pruebas}

Un medio de prueba es un instrumento que le otorga al juez el conocimiento de un hecho que conforma el tema de la prueba. Este último, a su vez, radica en los hechos que resulta necesario probar por estar estrechamente relacionados con el supuesto fáctico de la norma que se pretenda aplicar (Parra, 2006).

Entonces, el profesor Jairo Parra se refiere al principio de libertad de medios de pruebas en los siguientes términos:

La libertad probatoria consagrada lleva a concluir que los hechos y circunstancias del proceso pueden ser demostrados con cualquier medio que tenga esa capacidad, quedando por fuera la hipótesis de que determinado hecho sólo se puede establecer a través de un especial medio de convicción. (2006, p. 15)

Con relación a lo anterior, podemos observar que el legislador dejó la puerta abierta para aquellos medios de prueba que tengan vocación para demostrar algún hecho materia del proceso en curso, dejando un margen de maniobra en el cual caben muchas alternativas de las cuales valerse. En materia internacional, el Sistema Interamericano de Derechos Humanos se ha referido a la libertad probatoria en los siguientes términos: "Consiste en que la prueba debe poder decretarse, practicarse y aportarse al proceso con absoluta libertad, recordando que si el objeto de la prueba es la verificación, esta debe darse con absoluta confianza y libertad" (Barbosa, 2002, pp. 213, 215).

Así las cosas,

la potestad de señalar los medios de prueba procesalmente admisibles, lo mismo que su mérito o valor, le corresponde exclusivamente al legislador y al juez, pero a este solo en el caso de que esté autorizado por aquel: se trata de una materia de orden público que forma parte de la actividad jurisdiccional del Estado y de la regulación del proceso. (Devis, 2015, p. 536) 
Respecto de las pruebas directas o representativas, estas encarnan la realidad. Por ejemplo, una fotografía, un video o un testimonio son pruebas directas por cuanto suponen una representación homogénea de la realidad. Mientras tanto, la prueba indirecta o crítica no guarda parecido alguno con la realidad, pero le permite al juez establecer un vínculo racional y asociativo con los hechos que se pretende demostrar.

\section{Flexibilización probatoria en la jurisprudencia}

\section{En el Consejo de Estado}

Para llegar a la adopción de la flexibilización probatoria la consideración recurrente en toda la jurisprudencia del Consejo de Estado $^{6}$ se relaciona con los múltiples obstáculos que deben enfrentar las víctimas de infracciones a los derechos humanos y al derecho internacional humanitario. Por ello se hace obligatorio para el juez de daños actuar como juez de convencionalidad, en atención a la fuerza vinculante de los tratados en materia de derechos humanos — pacta sunt servanda- Corolario de esto es que el

objetivo se centra en que el sentido y alcance de la protección de los derechos constitucionales fundamentales sea fijado en concordancia con lo establecido por la Convención Interamericana de Derechos Humanos, teniendo en cuenta no solo lo dispuesto en el tratado, sino la interpretación que del mismo [sic] ha hecho la Corte Interamericana de Derechos Humanos. ${ }^{7}$ (Consejo de Estado, Sección Tercera, 2013)

Ahora bien, la misma sentencia da luces sobre la justificación constitucional de la flexibilización del estándar probatorio. Manifiesta la corporación que se hace por dos razones:

6 De conformidad con Vargas (2018), "el Consejo de Estado colombiano es la máxima autoridad en materia contenciosa administrativa, caracterizado por ser el único que, en América Latina, cumple funciones jurisdiccionales y consultivas a la vez, como sucede en Italia y Grecia, pero paradójicamente diferente en su naturaleza al de Francia”.

7 Consejo de Estado, Sección Tercera (2013). Sentencia del 27 de septiembre. Exp. 19939 [C. P. Stella Contos Díaz del Castillo]. 
1) Cuando se trata de reparar los delitos más graves considerados por el derecho internacional (CPI, 2002, art. 5) los principios de justicia, verdad y reparación integral han sido considerados por la Corte IDH como derechos fundamentales. Para la protección de estos no se pueden alegar obstáculos de orden interno, habida cuenta de que ostentan el carácter de norma de ius cogens. Sobre el particular, esta sala especializada manifiesta que el deber de garantía de los derechos de las víctimas se infringe si no se examinan las circunstancias del caso concreto a la luz del principio de equidad, lo que impone simultáneamente aplicar criterios tales como el de buena fe, favor debilis y el de efectividad de la indemnización integral. Ello, entre otras, dada la naturaleza misma del delito (Consejo de Estado, Sección Tercera, 2013).

2) En razón del deber de protección que impone el artículo 13 superior, en la construcción que se ha hecho en torno al escenario constitucional de la igualdad, cuando una persona se encuentra en medio de una relación asimétrica y ocupa en esta la posición más débil, se hace acreedora a una mayor protección y soporte por parte del ordenamiento jurídico.

Consciente el Tribunal Supremo de la jurisdicción de lo contencioso administrativo del marco situacional en virtud del cual se dieron las violaciones a los DD. HH. y al DIH en el conflicto armado en Colombia, manifiesta que es deber del juez administrativo acudir a criterios flexibles y privilegiar la valoración de los medios de prueba indirectos, a fin de alcanzar la verdad histórica de los hechos y lograr la satisfacción de los derechos fundamentales de las víctimas. En el entender del alto tribunal, y acogiendo la postura de la Corte IDH, es el Estado el que tiene el control de los medios de prueba para esclarecer lo ocurrido, conforme a los siguientes términos:

A diferencia del derecho penal interno, en los procesos sobre violaciones de derechos humanos la defensa del Estado no puede descansar sobre la imposibilidad del demandante de allegar pruebas que, en muchos casos, no pueden obtenerse sin la cooperación del Estado. (Corte IDH, 1988) 
En concordancia con el papel del juez de convencionalidad, entiende esta corporación judicial que el juez goza de una gran flexibilidad para la valoración de la prueba, en los mismos términos que lo dijera la Corte IDH en el Caso Mapiripán vs. Colombia, donde se determina que los tribunales internacionales gozan de una amplia potestad para apreciar y valorar las pruebas de acuerdo con las reglas de la sana crítica, la lógica y la experiencia, con el fin de evitar adoptar una determinación demasiado rígida del quantum probatorio necesario para justificar un fallo (Corte IDH, 2005).

En concordancia con lo ya expuesto aquí, el alto tribunal señala que en casos en los cuales la parte que cuenta con legitimación por activa sea víctima del conflicto armado el juez de daños está obligado a incorporar en su interpretación y aplicar directamente estándares desarrollados por organismos internacionales de protección de derechos humanos.

Si bien es cierto que los sistemas internacionales de protección de derechos humanos son subsidiarios respecto de los nacionales, se necesita amparar a la víctima in extenso, así como en las intersecciones axiológicas que existen entre el juez interamericano y el juez de daños en lo contencioso administrativo, ya que este último está instituido como un juez de derechos humanos que tiene el deber de proteger a todas las personas del daño antijurídico que le sea imputable derivado del incumplimiento de las obligaciones nacionales o de derecho internacional (Consejo de Estado, Sección Tercera, 2014). "Ahora bien, estas obligaciones internacionales, de estricto cumplimiento y de aplicación directa, son plenamente aplicables al juicio interno de responsabilidad estatal, habida cuenta de que el juez contencioso administrativo se encuentra vinculado a un estricto control de convencionalidad" (Consejo de Estado, Sección Tercera, 2014) ${ }^{8}$.

Siguiendo lo dicho en el párrafo precedente, el Consejo de Estado adopta una de las principales reglas de la Corte IDH sobre el particular, dando eficacia probatoria a

8 Sobre el tópico de los medios de prueba, ver también Consejo de Estado, Sección Tercera (2015), donde se da plena eficacia a la declaración de una de las partes dentro de un proceso sin que se surtiera el correspondiente interrogatorio de parte. 
medios de conocimiento que en principio no tendrían aptitud para ello. A modo de ejemplo se muestra el siguiente fragmento jurisprudencial:

En lo concerniente a las actuaciones adelantadas por los demandantes ante diversos organismos oficiales, a fin de que se investigara y se sancionara a los responsables; la Sala conferirá valor probatorio a estas actuaciones, las cuales, si bien en lo respectivo a las manifestaciones allí consignadas no constituyen una declaración de parte ni reúne[n] las condiciones de un testimonio bajo las exigencias del Código de Procedimiento Civil, serán tenidas en consideración como elementos probatorios documentales y declarativos, que deberán ser contrastados con el conjunto de pruebas que obren en el proceso. (Consejo de Estado, Sección Tercera, 2014)

Finalmente, los últimos pronunciamientos del Consejo de Estado sobre este tema han estado dirigidos a reiterar la aptitud de los medios probatorios indirectos, específicamente de la prueba indiciaria, en procesos en los cuales se pretenda reparar a víctimas de violaciones de DD. HH. y DIH (Consejo de Estado, Sección Tercera, Subsección A, 2017a; Subsección A, 2017b; Subsección B, 2017), Sin embargo, aun cuando se han venido adaptando dichos mecanismos de valoración de la prueba indirecta, al momento de tratarse elementos probatorios como los recortes de prensa el quantum que constantemente se les ha otorgado es el de documentos que acreditan el mero hecho de que determinada información ha sido publicada pero no gozan de entidad suficiente para probarla (Consejo de Estado, Sección Tercera, 2017).

Aun así, si bien es dable que individualmente los recortes de prensa no gocen del suficiente valor probatorio para determinar la responsabilidad del Estado, o de un agente particular, son una herramienta indiscutible que debe ser tenida en cuenta para la construcción de contextos que tengan vocación de acreditar siquiera presunciones sobre prácticas violatorias a los derechos humanos. En otras palabras, los elementos de prueba que individualmente no tengan vocación probatoria, cuando se valoran en conjunto podrían ser determinantes para la acreditación o presunción de los hechos. 


\section{En la Corte Suprema de Justicia, Sala de Casación Penal}

Entre la jurisprudencia de la Corte Suprema se encuentra que las sentencias sobre el particular se construyeron bajo la óptica del proceso penal especial de la Ley 975 de 2005, en la cual se señala el uso de la flexibilización probatoria estrictamente para lo relativo a dicho proceso.

La adopción de los cánones de flexibilización probatoria se hace únicamente en el entendido de privilegiar la valoración de medios probatorios indirectos, lo que contrasta con las consideraciones del Consejo de Estado sobre este tema, que en aras de proteger in extenso los derechos de las víctimas pretende emular el papel activista que ostenta la Corte IDH en el ámbito de su competencia contenciosa.

Para la construcción de este aparte realizamos la lectura y análisis de múltiples providencias de esta sección de la Corte Suprema de Justicia. En torno al particular, la sala en forma tranquila y reiterada, señala, dando uso al principio de equidad y a los cánones que impone el artículo 13 constitucional, que para el ejercicio de flexibilización probatoria resulta útil acudir a lo siguiente:

1) Hechos notorios: los cuales tienen validez en el ámbito del proceso penal, habida cuenta de la remisión normativa, que señalan los estatutos procesales penales, a los demás ordenamientos procesales, entre ellos el civil. El carácter demostrativo de aquellos se fundamenta en acreditar una situación concreta conocida de manera general por la ciudadanía y por el juez en el marco del proceso, siempre que guarde pertinencia de especial carácter en el sentido de la decisión que se adopta.

2) Juramento estimatorio: en el proceso de Justicia y Paz tiene cabida en atención a los principios de integración y de complementariedad dispuestos en la Ley 975 de 2005. La apreciación del medio de prueba en comento supone que la víctima valore en concreto el valor del daño por ella sufrido. Si se da la situación en que el estimatorio no sea controvertido por el otro extremo de la litis, debe tenerse por fijada la suma a indemnizar. 
Lo anterior tiene un condicional, y es que las pruebas que obren a lo largo del plenario desvirtúen la suma pretendida. La Sala de Casación Penal de la Corte Suprema de Justicia entiende que debe mediar una acreditación siquiera precaria, lo que la lleva a concluir lo siguiente:

Si bien el juramento estimatorio depende en buena medida de cuánto exprese el demandante y de la oposición que sobre el particular formule el postulado, lo cierto es que en estos casos los funcionarios judiciales en su papel proactivo no pueden atenerse simple y llanamente a cuanto dijo aquel, pues les corresponde constatar que hay medios de prueba cuya apreciación permite dar fundamento material a dichas afirmaciones, garantizando con ello que la forma no predomine, sin más, sobre la materialidad y sustancialidad, según lo dispone el artículo 228 de la Carta Política. (Corte Suprema de Justicia, Sala de Casación Penal, 2011)

3) Modelos diferenciados o baremo: en casos de violaciones sistemáticas de derechos humanos, como las acaecidas en el marco del proceso de Justicia y Paz, son de especial utilidad para cuantificar las reparaciones habida cuenta del desequilibrio de cara a la prueba en que se encuentran las víctimas. La adopción de estos modelos deviene en que luego de la demostración del daño sufrido podrá hacerse extensiva la cuantificación de este a quienes se encuentren en situaciones similares, pero no hubieren demostrado de la mejor manera el quantum de perjuicios sufridos? .

\section{4) Uso de presunciones:}

Las cuales comportarán la inversión de la carga de la prueba a favor de las víctimas, de modo que será del resorte de los postulados y sus defensores desvirtuar lo que con ellas se da por acreditado. Por ejemplo, cuando

9 El uso de estos modelos se justifica para garantizar la igualdad en los términos del artículo 13 constitucional, siempre y cuando los peticionarios se encuentren en situaciones inter pares, pues se debe entender el devenir de las circunstancias personalísimas que sufre cada víctima para poder determinar lo merecido por cada una. 
desconociendo el ingreso percibido por un trabajador se presume que devenga el salario mínimo. (Corte Suprema de Justicia, Sala de Casación Penal, 2011)

5) Uso de reglas de la experiencia: como instrumento de apreciación de las pruebas, supone que el juez evidencie un proceder generalizado y repetitivo dentro del marco fáctico del proceso que se pone en su conocimiento. Tales reglas responden al postulado Siempre o casi siempre que se presenta $A$, entonces sucede $B$. Así las cosas, su uso se circunscribe a la realización de pronósticos y diagnósticos.

De acuerdo a las disposiciones de esta sala especializada, el deber de flexibilizar las reglas de apreciación probatoria se ejerce en el entendido de materializar el derecho a la igualdad de las víctimas, pues resulta evidente la desventaja en que se encuentran de cara a aparatos criminales organizados. El fin de ello no es privilegiar la discrecionalidad ilimitada del sentenciador, sino afinar sus métodos de ponderación.

\section{En la Corte Interamericana de Derechos Humanos}

Desde su primera sentencia de fondo, en 1988, la Corte IDH ha insistido en que los tribunales internacionales deben tener criterios menos formales en la valoración de las pruebas que los de los sistemas internos, habida cuenta de que los primeros reconocen graduaciones diferentes que dependen de la naturaleza y la gravedad del litigio (Corte IDH, 2006).

Es importante destacar que, si bien se tiende a dar una especial preponderancia al principio pro hominem y al uso de las reglas de equidad, en materia probatoria el sistema de este tribunal descansa en el principio de contradicción y el de libre apreciación probatoria. En primera medida, en lo que atañe a las pruebas rige el principio de onus probandi, el cual señala que la carga de la prueba corresponde a la parte que alega ${ }^{10}$. Sin embargo, en el procedimiento ante este tribunal existe cierto

10 Es tal la aplicación que, en algunos casos, la corte ha exonerado de forma total la responsabilidad internacional del Estado por violación de la Convención Americana sobre Derechos Humanos. V. g.: caso Fairén Garbi y Solís Corrales en 1989. 
grado de inversión de la carga de la prueba, pues en cuestiones preliminares, de fondo y de reparaciones corresponde al Estado allegar las pruebas que solo puedan recabarse con su cooperación (Corte IDH, 1988).

Otra cosa a reseńar es la multiplicidad de sujetos de prueba dentro del proceso interamericano, pues de la lectura sistemática del reglamento de la Corte IDH se colige que le es dable aportar pruebas dentro de las etapas procesales a la $\mathrm{CIDH}$ (Comisión Interamericana de Derechos Humanos), el Estado y a las víctimas a través de su representante.

En lo referente a los medios de prueba en concreto, se aprecian algunas particularidades, como las siguientes:

1) Prueba documental: sobre este medio de conocimiento hay dos particularidades respecto de los procesos internos, a) la posibilidad de valorar con las demás pruebas que obran en el plenario documentos que se alleguen en forma extemporánea, siempre y cuando la corporación los encuentre útiles para resolver el caso (Corte IDH, 2007, parrs. 42-44), y b) la posibilidad de analizar como prueba documental el testimonio que no cumple con los requisitos del reglamento de la Corte, tal como ocurrió en el caso Valle Jaramillo vs. Colombia ${ }^{11}$.

11 "El 23 de abril de 2008 los representantes presentaron prueba documental adicional consistente en dos declaraciones rendidas por el señor Francisco Enrique Villalba Hernández en febrero y marzo de 2008 en el marco de un proceso penal que se lleva a cabo a nivel interno, las cuales contienen información presuntamente relacionada al [sic] presente caso, y por tanto solicitaron su incorporación al acervo probatorio en calidad de prueba superviniente (supra párr. 10). Al respecto, el Estado señaló que las referidas declaraciones no han sido corroboradas ni valoradas por la fiscal de conocimiento, no cumplen los requisitos de una prueba en los términos del artículo 44 del Reglamento de la Corte, y no han sido contradichas a nivel del proceso interno. Además, el Estado cuestionó la validez de las declaraciones alegando la poca credibilidad del señor Villalba. La Corte considera que dicha prueba documental cumple con los requisitos formales para su admisibilidad como prueba superviniente, conforme al artículo 44.3 del Reglamento, y la incorpora al acervo probatorio para su valoración, para lo cual tendrá en cuenta las objeciones seńaladas por el Estado” (párr. 60). 
2) Prueba testimonial: sobre el particular la regla general es que los testimonios se reciban en la sede de la corte. No obstante, en algunas situaciones es posible recogerlos en otro lugar en presencia de un delegado de la corporación.

Una particularidad evidenciable sobre este punto es que la corte puede escuchar a título informativo a una persona que esté imposibilitada para testimoniar, siempre y cuando se considere que su declaración tiene relevancia en relación con el objeto de prueba.

3) Recortes de prensa: "No puede dárseles el carácter de prueba documental propiamente dicha. Muchos de ellos, sin embargo, constituyen la manifestación de hechos públicos o notorios que como tales no requieren prueba”(Corte IDH, 1988). Así las cosas, resultan de importancia cardinal dentro del proceso interamericano por su gran valor demostrativo, pese a que de suyo no constituyen un medio de prueba en concreto.

\section{ANÁlISIS DEL CONTEXTO COMO MEDIO DE PRUEBA}

Desde el comienzo de su etapa republicana Colombia ha sufrido innumerables guerras civiles y conflictos armados internos, todos producto de diferencias en las ideas políticas. Por ello, el estudio del derecho no ha sido extraño a la violencia, sino que, más allá de la Constitución Política, varias instituciones jurídico-procesales colombianas han sido exclusivamente diseñadas pensando en los conflictos internos y sus víctimas ${ }^{12}$.

Dentro del amplio margen de la prueba indirecta se puede encontrar el indiciocontexto. Producto de nuestro análisis, es evidente que no es totalmente correcto hablar de una "prueba de contexto" per se, sino de las conjeturas que se pueden hacer a partir del análisis de un contexto. Así las cosas, de acuerdo con la RAE (2017a), el contexto es un "entorno físico o de situación, político, histórico, cultural o de cualquier otra índole en el que se considera un hecho", mientras que un indicio

12 Restitución de tierras, Justicia y Paz, Jurisdicción Especial para la Paz, entre otros contenidos normativos. 
es un "fenómeno que permite conocer o inferir la existencia de otro no percibido" (2017b).

Desde el punto de vista de las ciencias jurídicas el contexto se ha venido tratando como

una herramienta que facilita el derecho a la verdad, del cual son titulares tanto la víctima como la sociedad, pues apunta a que se determine de manera precisa cómo tuvieron ocurrencia los hechos en general, sus autores, sus motivos, las prácticas utilizadas, los métodos de financiación, las colaboraciones internacionales, estatales o particulares recibidas, a fin de que salga a la luz pública ese acontecer soterrado que debe exponerse a la comunidad para que implementen los correctivos necesarios en orden a impedir la reiteración de tales sucesos, así como establecer dónde se encuentran los secuestrados y los forzosamente desparecidos, amén de integrar de la manera más fidedigna posible la memoria histórica. (Corte Suprema de Justicia, Sala de Casación Penal, 2015)

De la misma manera, la Unidad Nacional de Análisis y Contextos define el contexto como un

marco de referencia contentivo de aspectos esenciales, acerca de elementos de orden geográfico, político, económico, histórico y social, en el cual se han perpetrado delitos por parte de grupos criminales, incluidos aquellos en los que servidores públicos y particulares colaboran con aquellos. Debe igualmente comprender una descripción de la estrategia de la organización delictiva, sus dinámicas regionales, aspectos logísticos esenciales, redes de comunicaciones y mantenimiento de redes de apoyo, entre otros. No bastará con la descripción de la estructura criminal o una enunciación de sus víctimas, sino que se deberá analizar su funcionamiento. (Fiscalía General de la Nación, 2012)

Dentro del SIDH se ha usado el análisis del contexto como una manifestación de la prueba indiciaria o circunstancial desde su primera sentencia de fondo, en el caso Velásquez Rodríguez vs. Honduras. Dicho caso versa sobre la responsabilidad internacional de Honduras en la desaparición forzada de Ángel Manfredo 
Velásquez Rodríguez. Acá la CIDH, que actúa como un ente acusador, usó en primera medida testimonios de legisladores, abogados y víctimas de violaciones a los derechos humanos para demostrar que los recursos judiciales existentes en la época de la desaparición de Manfredo no eran eficaces para obtener la libertad de una persona privada injustificadamente de esta o desaparecida forzosamente (Corte IDH, 1988).

De la misma manera, la CIDH aportó recortes de prensa, testimonios y documentos en donde se hacía referencia a la existencia de cementerios clandestinos y desapariciones forzadas producto de cuestiones ideológicas, políticas o sindicales entre 1981 y 1984. Con esto la Corte IDH acreditó que en ese periodo existía una práctica sistemática y selectiva de desapariciones forzadas con amparo o tolerancia del poder público, además de afirmar que Manfredo Velásquez fue víctima de esa práctica, y que muy posiblemente había sido torturado, ejecutado y sepultado de manera clandestina por agentes de las Fuerzas Armadas (Corte IDH, 1988).

En la misma providencia la corte determina que cuando se comprueba la existencia de una práctica determinada, consciente y sistemática, es posible, haciendo uso de la prueba circunstancial, demostrar la violación de los derechos humanos de una persona en particular (Corte IDH, 1988). En el mismo sentido, la corte afirma que la prueba circunstancial, los indicios y las presunciones pueden ser legítimamente consideradas y usarse para fundamentar la sentencia, siempre y cuando de ellas puedan inferirse conclusiones consistentes sobre los hechos (Corte IDH, 1988) apoyándose en el uso de las reglas de la sana crítica y la lógica.

Otro caso emblemático es el de la masacre de Pueblo Bello vs. Colombia, que relata la desaparición de 43 campesinos oriundos del corregimiento de Pueblo Bello, municipio de Turbo, a manos de un grupo paramilitar liderado por Fidel Castaño Gil. El 14 de enero de 1990 aproximadamente 60 individuos dotados con armas de diferentes calibres y usando prendas privativas de las Fuerzas Militares incursionaron violentamente en la población. Luego de tomarse el corregimiento y saquear varias viviendas apartaron selectivamente a los campesinos; los amordazaron, amarraron y obligaron a subir a dos camiones en los cuales fueron llevados a una finca propiedad 
de Castaño Gil, en la vía que de Pueblo Bello conduce a San Pedro de Urabá (Corte IDH, 2006).

Se demostró que en el periodo en el que ocurrieron los hechos, en dicha carretera se encontraba un retén militar. Por ello, el indicio y el contexto aportados mediante un dictamen pericial fueron eje central de la decisión de la corte, primero, al momento de dictar la declaratoria de responsabilidad del Estado de Colombia. En efecto, si bien no se logró acreditar una participación directa u omisiva de los elementos de las fuerzas militares que se encontraban en dicho retén, haciendo uso de la lógica y la experiencia - el hecho de que dicha carretera fuese la única posible para el desplazamiento de los rehenes- permitió inferir, como mínimo, la omisión de la obligación de Colombia de proteger los derechos humanos contenidos en la $\mathrm{CADH}$.

En segunda medida, el contexto sirvió para acreditar que la zona era de alta influencia paramilitar, que los campesinos desaparecidos se dedicaban a prácticas agrícolas y que mediante esta actividad económica contribuían al sostenimiento de sus familias. Con base en esto, la Corte IDH tasa el perjuicio patrimonial haciendo uso de la equidad ${ }^{13}$ para liquidar la indemnización correspondiente a cada víctima y allegado del desaparecido (Corte IDH, 2006).

En el escenario internacional los contextos se usan frecuentemente, entendidos como una herramienta que busca cerrar la brecha de un conflicto, en los procesos de justicia transicional. Asimismo, se usan los elementos de la verdad, la justicia, la reparación y las garantías de no repetición para alcanzar la reconciliación y la paz en la sociedad (Santa, 2016). Al ser la verdad un elemento esencial y trasversal para los derechos de las víctimas, el contexto es una herramienta supremamente útil y casi obligatoria en cualquier transición de una sociedad, y en estos casos se vuelve más perceptible el interés de la sociedad en el proceso judicial.

13 En ese mismo sentido, caso Romero Blanco y otros vs. Venezuela, párr. 87; caso García Asto y Ramírez Rojas vs. Perú, párr. 278; caso Gómez Palomino vs. Perú, párr. 131. 
El interés de la sociedad en el proceso, pasados los tiempos de violencia sistemática, ya no radica en evitar los conflictos básicamente porque estos ya se han causado, sino en la cimentación de unas bases sólidas para la reconstrucción de país y la recuperación de la dignidad colectiva. Esto solo se logra instituyendo memoria histórica. Por ello, la prueba deja de pertenecer al proceso y es acogida por la sociedad. Es en este instante que el objeto del proceso empieza a transformarse. La necesidad de la búsqueda de la verdad material y la certeza histórica se convierte en el real fin de los procesos de posconflicto.

La justicia, si bien ciega, debe por un instante quitarse su venda para dar a la víctima esperanza de la garantía de sus derechos. La mayor garantía para las víctimas radica en la búsqueda de la verdad en su totalidad, de manera alguna en forma parcial; o se busca hasta que se encuentra o lo que se busca no es la verdad (Carnelutti, 1982). En el mismo sentido, Carnelutti (1982) afirmó que: "La verdad es como el agua: o es pura o no es verdad"; el papel del juez debe ser totalmente inquisitivo y garantista con el fin de obtener la verdad real.

Si se traen estas premisas a la realidad, es claro que luego de un conflicto armado, con todas sus aristas y complejidades, es imposible la consecución de una verdad absoluta e irrefutable, pero no por ello se deben dejar de hacer los máximos esfuerzos posibles para alcanzarla. Con todo esto, la verdad dentro de un proceso judicial, y más aún en la esfera de los derechos humanos, debe ser un mandato de optimización, como si se tratase de un principio.

Esta necesidad de optimización lleva a que el poder del juez deba tornarse inquisitivo y exige el máximo uso posible del poder jurisdiccional del Estado para lograr libertad en la valoración de la prueba. De la misma manera, implica que existan reales posibilidades de hacer uso de las reglas de la experiencia y la lógica para recorrer el camino de lo abstracto a lo concreto con la mayor seguridad posible para garantizar los derechos de todos los intervinientes en el pleito judicial.

Para hacer efectiva la verdad material y lograr un tránsito hacia la paz que garantice los derechos de las víctimas es necesario hacer extensivo el uso de la flexibilización probatoria, el contexto y los criterios de priorización, más allá de los procesos de 
justicia transicional y de lo contencioso administrativo, en la jurisdicción ordinaria. Más precisamente, cuando se pretenda determinar el grado de responsabilidad penal en asuntos en los cuales dicha jurisdicción está conociendo fenómenos de macrocriminalidad y delitos de lesa humanidad que por antonomasia no podría conocer un tribunal de justicia transicional.

\section{DE LA DIGNIDAD HUMANA Y LOS DERECHOS DE LAS VÍCTIMAS}

Tal vez el derecho a la dignidad sea el más abstracto del que puede gozar un ser humano, porque es allí donde nacen todos los derechos: a la vida, a la libertad, a las garantías judiciales, a la igualdad ante la ley, a la educación, a la vivienda (Medina, 2004), a un recurso efectivo — que es de donde derivan los derechos de las víctimas-, etc.

Aun cuando ni en la Declaración Universal de los Derechos Humanos ni en la Convención Americana de Derechos Humanos se hace una mención expresa a los derechos de las víctimas (O’Donnell, 2004), la jurisprudencia de la Corte IDH considera que estos revisten la calidad de fundamentales. De la misma manera, la Declaración sobre los Principios Fundamentales de Justicia para las Víctimas de Delitos y del Abuso del Poder establece reglas para determinar la calidad de víctima y para que las víctimas logren un acceso efectivo a la justicia y a un trato justo, indemnizaciones, asistencia, etc. (ONU, Asamblea General, 1985). En el mismo sentido, se ha dicho que los derechos de las víctimas se manifiestan en

- Verdad, por ejemplo, al "esclarecimiento de los hechos violatorios y las responsabilidades correspondientes"; este es, a la vez, un "derecho de carácter colectivo que permite a la sociedad tener acceso a información esencial para el desarrollo de los sistemas democráticos y [...] un derecho particular para los familiares de las víctimas, que permite una forma de reparación, en particular, en los casos de aplicación de leyes de amnistía". El derecho a la [verdad] posteriormente ha sido reconocido, en particular con respecto al destino de los desaparecidos, por la jurisprudencia (nacional e internacional), por instrumentos de derechos humanos y por la práctica de los Estados, la 
última, evidenciada en particular por el establecimiento de comisiones de verdad y reconciliación. Sobre este trasfondo puede concluirse con seguridad que el derecho a la verdad es una norma consuetudinaria emergente y un principio general del derecho.

- Justicia, a saber, alguna forma de protección judicial o mediante el acceso al sistema jurídico del Estado infractor (el cual — de acuerdo con la jurisprudencia de derechos humanos - tiene un deber de investigar, perseguir y sancionar a los responsables) o mediante un foro (público) alternativo donde la víctima pueda confrontar y desafiar a los autores.

- Reparación, usado como un término genérico que abarca la restitución plena (restitutio in integrum), la compensación [...], la rehabilitación, la satisfacción y garantías de no repetición y otras medidas, a saber, resumidamente, medidas que tienden al pleno reconocimiento del estatus de víctima y, en el grado que sea posible, el restablecimiento de sus derechos. (Ambos, 2009; primer énfasis añadido)

\section{FLEXIBILIZACIÓN PROBATORIA EN PROCESOS DE JUSTICIA TRANSICIONAL Y EL PROCESO PENAL ORDINARIO}

El uso de herramientas de flexibilización probatoria dentro de la etapa de conocimiento del proceso penal resulta poco común, porque el conflicto de principios y derechos naciente de este choque imposibilitaría limitar derechos como la presunción de inocencia (Corte Constitucional, 2012). En procesos de justicia transicional es habitual pensar en flexibilización probatoria, y es jurídicamente viable. Ejemplo de lo anterior es, en el marco del proceso penal de la Ley 975 de 2005, el uso de hechos notorios y la flexibilización de los umbrales probatorios en términos de la confesión al momento de la imputación:

En materia de Justicia y Paz, tanto la comprobación del dańo perpetrado como la comprobación del relato del postulado en la realización de las confesiones deben analizarse desde la perspectiva de la flexibilización de las exigencias de los 
medios de prueba en contraposición con la forma permitida tradicionalmente.

(Corte Suprema de Justicia, Sala de Casación Penal, 2009)

Respecto de la presunción de inocencia, esta goza también de tres dimensiones. Una se refiere a la manera en que se determina la responsabilidad penal, y en particular la carga de la prueba. Otra concierne a la imputación de responsabilidad penal (por participación en hechos delictivos) a un individuo que no ha sido juzgado. La tercera consiste en algunos corolarios relativos al trato de personas bajo investigación por un delito y a presos sin condena (O’Donnell, 2004; CIDH, 1996).

En el caso de los procesos penales especiales de Justicia y Paz, que nacen del "proceso de paz” con las AUC (Autodefensas Unidas de Colombia), a priori también es posible el uso de herramientas de flexibilización probatoria en la etapa del incidente de reparación integral, que se da ante el magistrado con función de control de garantías antes de proferir la sentencia condenatoria. En esta etapa, el uso de la flexibilización probatoria también reviste suma importancia, pues es cuando la víctima tiene la posibilidad de satisfacer su derecho a la reparación en sede judicial.

El incidente de reparación integral del proceso penal de la Ley 906 de 2004, a diferencia del de la Ley 975 de 2005, inicia luego de desvirtuar la presunción de inocencia del imputado. Por ello, en sentido abstracto el juez deja de tener funciones de conocimiento para convertirse en un juez de daños. En este escenario también debería ser posible el uso de herramientas de flexibilización probatoria, en virtud de los criterios de equidad y garantía de los derechos de las víctimas, claro está, de manera restringida a los casos relativos a violaciones graves de los derechos humanos.

En materia de violaciones graves a los derechos humanos, el juez penal, al momento de convertirse en un juez de daños, debe asumir también la posición de un juez de convencionalidad integrando los mandatos de la Corte IDH en los mismos términos en los que los ha adoptado el Consejo de Estado en su jurisprudencia de unificación. 
Y es que no se puede olvidar que los delitos más graves no son de conocimiento exclusivo de los tribunales de justicia transicional, pues ellos gozan de reglas de conocimiento y exclusión, así que existe la posibilidad de que miembros de grupos armados ilegales que hayan cometido crímenes atroces y delitos de lesa humanidad no integren el proceso de justicia transicional y tengan que ser juzgados por la jurisdicción ordinaria. En ese sentido, el parágrafo segundo del artículo primero del Marco Jurídico para la Paz señala:

En ningún caso se podrán aplicar instrumentos de justicia transicional a grupos armados al margen de la ley que no hayan sido parte en el conflicto armado interno, ni a cualquier miembro de un grupo armado que una vez desmovilizado siga delinquiendo. (Congreso de la República, 2012)

Es por esta razón que los criterios de flexibilización probatoria que se han venido desarrollando con ocasión de los procesos de justicia transicional también deben ser extensivos al proceso penal de la Ley 906 de 2004, incluido el incidente de reparación integral. La garantía de los derechos de las víctimas no puede depender del modelo procesal del juicio penal, sino de la gravedad de la afectación a su derecho.

En términos generales, el uso del análisis del contexto para determinar el modus operandi, las cadenas de mando o la responsabilidad de los máximos culpables de violaciones a los derechos humanos no supondría una grave violación a principios de rango constitucional, porque, en primera medida, el fin de Justicia y Paz no radica en un debate probatorio para desvirtuar la presunción de inocencia más allá de cualquier duda razonable, sino que, por el contrario, versa sobre el sometimiento a la justicia a cambio de beneficios judiciales con el fin de promover un tránsito a la democracia, la incorporación a la vida civil y la construcción de memoria histórica. Así las cosas, en virtud de la inexistencia de un debate probatorio tradicional no es dable discutir los principios en sentido estricto, como si del proceso de la Ley 906 de 2004 se tratase.

Contrario al proceso penal especial de Justicia y Paz, donde es un requisito esencial la confesión y la aceptación de cargos so pena de que el caso sea conocido por la jurisdicción ordinaria, la JEP, que nace del Acuerdo Final para la Terminación 
del Conflicto y la Construcción de una Paz Estable y Duradera entre el Estado Colombiano y las Farc-EP, no prevé un sometimiento a la justicia en esos términos. Si bien será posible obtener beneficios jurídicos con base en la confesión de delitos, el aporte para la construcción de una verdad plena, la reparación y las garantías de no repetición, en virtud de los criterios de justicia restaurativa que conforman los cimientos del proceso de justicia transicional, en la JEP sí deberá existir un debate probatorio, y quienes se sometan a la jurisdicción deben ser vencidos en juicio para que se les aplique la sanción correspondiente (Mesa de Conversaciones para la Terminación del Conflicto, 2016). De la misma manera, los criterios de flexibilización probatoria y uso del contexto en los términos de la jurisprudencia interamericana se deben adoptar de lleno en este proceso de justicia transicional.

Tal y como se ha expuesto en múltiples ocasiones a lo largo de este escrito, el uso de contextos tiene como objetivo primordial la garantía de los derechos de las víctimas y la consecución de una verdad material histórica que funja como medida de satisfacción luego de la grave violación de un derecho fundamental, además de servir como herramienta de flexibilización probatoria dentro del trámite indemnizatorio del proceso penal. Se espera que la víctima, como consecuencia de esto, se sienta protegida y recupere la dignidad humana que le fue arrebatada con ocasión de un hecho excepcionalmente dañoso. Por ello, la reparación de los derechos de las víctimas trasciende el ámbito personal de estas para convertirse, de esa manera, en una medida de restauración del tejido social y de la nación.

\section{A MODO DE CONCLUSIONES}

\section{En la jurisdicción de lo contencioso administrativo (JCA)}

A diferencia del proceso penal, en el escenario de la JCA, el debate judicial no lleva al desmedro del derecho a la libertad, razón por la cual no existe punto de comparación en cuanto a garantías del sujeto pasivo se refiere. Sin embargo, es evidente que, producto de las dificultades en el ejercicio del monopolio de la violencia, el Estado colombiano es violador de derechos humanos, no solo en términos del incumplimiento de las 
obligaciones de no hacer que ha adquirido en virtud del derecho internacional general y el pacta sunt servanda, sino que se ha demostrado una conducta sistemática de afectación de las garantías fundamentales de los administrados, que puede traducirse en la existencia de un Estado criminal ${ }^{14}$.

Otro asunto para tratar en este acápite propositivo, es la concurrencia del Consejo de Estado y la Corte IDH como jueces naturales del Estado cuando de derechos humanos se trata, aun a sabiendas de la competencia subsidiaria del juez internacional. De ahí la trascendencia de la flexibilización probatoria en la JCA y la posición de juez de convencionalidad que debe asumir el juez de daños contencioso administrativo cuando tiene que decidir controversias relativas a violaciones de los derechos humanos.

En resumidas cuentas, es posible que el juez contencioso administrativo en materia de reparaciones directas producto de violaciones a los derechos humanos integre de pleno las reglas probatorias que ha creado la Corte IDH. Esto en virtud del control de convencionalidad y del deber de las autoridades, en el ámbito interno de los Estados, de garantizar la eficacia de los derechos más fundamentales ante la situación de debilidad manifiesta en la que se encuentran las víctimas, que en muchos casos no pueden acreditar fácticamente agravios a su dignidad humana (Consejo de Estado, Sección Tercera, 2014).

La construcción de contextos, y el análisis de estos, podría ser de gran ayuda para las víctimas en casos en los cuales, por ejemplo, no logran acreditar su condición de víctima para acceder a una reparación integral por no poder probar el daño emergente o el lucro cesante. Asimismo, en materia de daños inmateriales serviría para probar, por ejemplo, que la relación cercana a una víctima directa desaparecida produce congoja, tristeza y dolor.

14 Este actuar descuidado, irrespetuoso con las normas de derecho internacional público, podría llevar a que se calificase al Estado colombiano como delincuente o criminal, no en términos penales, sino de responsabilidad internacional del Estado, teniendo en cuenta la reiterativa comisión de ilícitos internacionales o violaciones graves por parte de funcionarios que actúan en nombre suyo. 
La subsiguiente critica al Consejo de Estado es la incongruencia con respecto al deber de "adecuar los criterios de valoración probatoria a los estándares establecidos por los instrumentos internacionales y las pautas creadas por la Corte Interamericana de Derechos Humanos en virtud del control de convencionalidad, esto en aras de garantizar una justicia efectiva" (Consejo de Estado, Sección Tercera, 2014), y el hecho de, en muchos casos, denegar la solicitud de indemnización del daño emergente o el lucro cesante presente y futuro.

Ello ocurre cuando no se prueba debidamente una situación que el juez bien pudo esclarecer con sus facultades inquisitivas y en la cual el análisis de un contexto le hubiera podido servir para acreditar, si quiera de manera sumaria, el daño, la culpa o el nexo causal para proceder a usar criterios de equidad en la cuantificación del daño no acreditado tradicionalmente, tal y como se hace en el marco de la competencia de la Corte IDH.

Conforme se ha venido desarrollando en el marco de las competencias de la Corte IDH, el uso de los dictámenes periciales para allegar al trámite del proceso la "prueba de contexto" es esencial para garantizar tanto la efectividad de la flexibilización probatoria como el derecho de las víctimas a la verdad. Por esto mismo, el juez contencioso administrativo debe tomar consciencia sobre su propio rol de garante de convencionalidad, y dada la complejidad de la elaboración de un contexto útil, debe apropiarse de sus facultades inquisitivas para designar a los expertos idóneos en la realización del contexto, esto sin siquiera acudir a normas de carácter internacional, sino por mandato del artículo 218 de la Ley 1437 de 2011.

Habiendo explicado la importancia del contexto en materia de derechos humanos, es imposible considerar la decisión judicial en materia contencioso administrativa como una forma de reparación per se, en el mismo sentido que se ha venido haciendo en la jurisprudencia interamericana, hasta cuando el análisis juicioso de un contexto en los términos de las disposiciones de la Corte IDH no se adopte de lleno por parte del juez interno, y hasta que la sentencia no se dé en virtud de un estudio transversal de las ciencias sociales a través del caso en concreto. 


\section{En los incidentes de reparación integral}

Si bien las funciones del juez penal no pueden ser comparables con las del juez contencioso administrativo, el proceso, ya sea ante la jurisdicción ordinaria o ante la de Justicia y Paz, también debe hacer uso de las herramientas de flexibilización probatoria. Y es que en el mismo momento en que se desvirtúa la presunción de inocencia del imputado y la víctima solicita se le repare ${ }^{15}$, el juez "cambia su toga" y deja de ser un juez de conocimiento para convertirse en un juez de dańos y, en materia de agresiones contra los derechos humanos, al mismo tiempo en un juez de convencionalidad.

Evitando todo el debate correspondiente al uso de la equidad y la flexibilización probatoria en la etapa de conocimiento —en el incidente de reparación integral—, cuando la carga probatoria deja de recaer en la Fiscalía para asentarse en la víctima el deber de aportar pruebas que acrediten la intensidad del daño causado con ocasión de una conducta típica, antijurídica y culpable, el juez penal debe, de la misma manera en la que lo haría el juez interamericano, adoptar medidas tangibles de flexibilización probatoria.

Los principios del sistema penal acusatorio-adversarial, relativos al papel del juez como un simple espectador que no tiene posibilidad de interferir dentro del proceso, no pueden ser concebibles dentro del trámite del incidente de reparación integral, puesto que, al ya haberse desvirtuado la presunción de inocencia en la etapa de conocimiento, el imputado deja de ser el eje central del proceso para permitir que la víctima se convierta en el objeto del procedimiento.

Aun cuando es aplaudible el uso de herramientas como el baremo, las presunciones o el juramento estimatorio dentro del proceso penal en su etapa reparatoria, es necesario que el juez penal de daños se torne más garantista. Así, cuando sea evidente que

15 En la competencia de la jurisdicción ordinaria la Ley 906 de 2004, en su artículo 102, determina que "emitido el sentido del fallo que declara la responsabilidad penal del acusado y, previa solicitud expresa de la víctima, o del fiscal o del Ministerio Público a instancia de ella, el juez fallador abrirá inmediatamente el incidente de reparación integral de los daños causados con la conducta criminal, y convocará a audiencia pública dentro de los ocho (8) días siguientes". 
alguna de las personas asiste al incidente como víctima en situación de indefensión (Corte Constitucional, 2015) — por ejemplo, al notarse la dificultad para allegar pruebas al procedimiento con el fin de acreditar, la dimensión y cuantía del daño causado-, el juez debe hacer uso de sus facultades inquisitivas dentro del incidente de reparación integral para decretar y practicar pruebas que conduzcan a determinar los elementos del daño que la jurisprudencia constitucional (Corte Constitucional, 2014) considera necesarios para el acceso a la pretensión indemnizatoria.

Así las cosas, si la víctima sujeto de especial protección constitucional y convencional no aporta una prueba necesaria, útil o pertinente, el juez debe proceder inmediatamente a decretarla de oficio apelando nada más que a su humanidad.

¿Cuáles son los pecados del juez penal? Con experiencia proveniente exclusivamente de la jurisprudencia de la Sala de Casación Penal de la Corte Suprema de Justicia nos hemos dado cuenta de la existencia de tarifas probatorias, específicamente relacionadas con el aporte del registro civil para acreditar la condición de víctima. Si bien la Sala de Casación Penal ha determinado que no es necesario flexibilizar este requisito por la facilidad con la que se puede obtener, no hay que desconocer que además de ser un sujeto procesal que merece un especial trato por su condición de debilidad, también se hace acreedor a la obligación de nosotros como sociedad de repararle, no en términos pecuniarios, sino en búsqueda del restablecimiento de su dignidad humana. Y la burocracia no es digna para la víctima.

\section{REFERENCIAS}

Ambos, K. (2009). El marco jurídico de la justicia de transición. En A. Kai y E. e. Malarino, Justicia de transición. Informes de América Latina, Alemania, Italia y España (pp. 41-44). Montevideo: Konrad Adenauer Stiftung.

Barbosa, F. (2002). Litigio interamericano. Bogotá: Universidad de Bogotá Jorge Tadeo Lozano. 
Carnelutti, F. (1982). La prueba civil. Buenos Aires: Depalma.

Castro, J. (2018). Alcance del principio iura novit curia en la responsabilidad del Estado colombiano. Via Inveniendi et Iudicandi, 13(1), 169-187. Doi: http://dx.doi.org/10.15332/ s1909-0528.2018.0001.06

CIDH (Comisión Interamericana de Derechos Humanos) (1996). Caso Martín de Mejía vs. Perú, informe del 1 de marzo de 1996.

Congreso de la República de Colombia (31 de julio de 2012). Acto Legislativo para la Paz [Acto Legislativo 01]. Diario Oficial, 48508.

Consejo de Estado, Sección Tercera (2013). Sentencia del 27 de septiembre. Exp. 19939 [C. P. Stella Contos Díaz del Castillo].

Consejo de Estado, Sección Tercera (2014). Sentencia de unificación del 28 de agosto. Exp. 32988 [C. P. Ramiro de Jesús Pazos Guerrero].

Consejo de Estado, Sección Tercera (2015). Sentencia del 12 de marzo. Exp. 30413 [C. P. Hernán Andrade Rincón].

Consejo de Estado, Sección Tercera (2017). Sentencia del 23 de marzo. Exp. 32988 [C. P. Ramiro de Jesús Pazos Guerrero].

Consejo de Estado, Sección Tercera, Subsección A (2017a). Sentencia del 23 de marzo. Exp. 44887 [C. P. Hernán Andrade Rincón].

Consejo de Estado, Sección Tercera, Subsección A (2017b). Sentencia del 23 de marzo. Exp. 50941 [C. P. Hernán Andrade Rincón].

Consejo de Estado, Sección Tercera, Subsección B (2017). Sentencia del 30 de marzo. Exp. 46440 [C. P. Danilo Rojas Betancourt].

Corte Constitucional (2012). Sentencia C-289 [M. P. Humberto Sierra Porto]. 
Corte Constitucional (2014). Sentencia C-286 [M. P. Luis Ernesto Vargas Silva].

Corte Constitucional (2015). Sentencia SU-636 [M. P. María Victoria Calle Correa]

Corte IDH (Corte Interamericana de Derechos Humanos) (29 de julio de 1988). Caso Velásquez Rodríguez vs. Honduras. Sentencia de fondo, reparaciones y costas.

Corte IDH (Corte Interamericana de Derechos Humanos) (15 de marzo de 1989). Caso Fairén Garbi y Solis Corrales vs. Honduras. Sentencia de fondo.

Corte IDH (Corte Interamericana de Derechos Humanos) (15 de septiembre de 2005). Caso Mapiripán vs. Colombia. Sentencia de fondo, reparaciones y costas.

Corte IDH (Corte Interamericana de Derechos Humanos) (22 de noviembre de 2005). Caso Gómez Palomino vs. Perú. Sentencia de fondo, reparaciones y costas.

Corte IDH (Corte Interamericana de Derechos Humanos) (25 de noviembre de 2005). Caso García Asto y Ramirez Rojas vs. Perú.

Corte IDH (Corte Interamericana de Derechos Humanos) (28 de noviembre de 2005). Caso Blanco Romero y otros vs. Venezuela.

Corte IDH (Corte Interamericana de Derechos Humanos) (31 de enero de 2006). Caso de la masacre de Pueblo Bello vs. Colombia. Sentencia de fondo, reparaciones y costas.

Corte IDH (Corte Interamericana de Derechos Humanos) (21 de noviembre de 2007). Caso Chaparro Álvarez y Lapo Íñiguez vs. Ecuador. Sentencia de excepciones preliminares, fondo, reparaciones y costas.

Corte IDH (Corte Interamericana de Derechos Humanos) (27 de noviembre de 2008). Caso Valle Jaramillo y otros vs. Colombia. Sentencia de fondo, reparaciones y costas.

Corte Suprema de Justicia, Sala de Casación Penal (12 de mayo de 2009). Auto interlocutorio del 12 de mayo de 2009. Exp. 31150 [M. P. Augusto José Ibáñez Guzmán]. 
Corte Suprema de Justicia, Sala de Casación Penal (2011). Sentencia del 27 de abril. Rad. 34547 [M. P. María del Rosario González de Lemos].

Corte Suprema de Justicia, Sala de Casación Penal (2015). Sentencia del 25 de noviembre. Rad. 45463 [M. P. José Luis Barceló].

CPI (Corte Penal Internacional) (2002). Estatuto de Roma.

Devis, H. (2015). Teoría de la prueba judicial. Tomo 1. Bogotá: Temis.

Fiscalía General de la Nación (2012). Directiva 0001 del 4 de octubre. Por medio de la cual se adoptan criterios de priorización de situaciones y casos, y se crea un nuevo sistema de investigación penal y de gestión de aquellos en la Fiscalía General de la Nación.

Fundación Tomás Moro (1991). Diccionario jurídico Espasa. Madrid: Espasa Calpe.

Joya, D. y Sánchez, A. (2018). Inseguridad jurídica ante el impedimento del ejercicio de la acción pública de inconstitucionalidad dentro del proceso especial para la paz. Revista Iusta, 1(48), 199-225. Recuperado de https://goo.gl/531Du2

Medina, C. (2004). Papá: ¿Qué es la dignidad humana? Aula Urbana, 46, 6-10.

Mesa de Conversaciones para la Terminación del Conflicto (2016). Acuerdo Final para la Terminación del Conflicto y la Construcción de una Paz Estable y Duradera. Bogotá.

Moreno, E. y Álvarez, W. (2017). Presupuestos políticos y jurídicos para la reparación integral de las víctimas de desplazamiento forzado en Colombia a causa del conflicto armado. Via Inveniendi et Iudicandi, 12(2), 117-147. Doi: http://dx.doi.org/10.15332/ s1909-0528.2017.0002.05

Murcia, T. (2018). La crisis del financiamiento del Sistema Interamericano de Derechos Humanos: una amenaza a la protección de derechos humanos en América. Verba Iuris, 13(39), 49-66. 
O’Donnell, D. (2004). Derecho internacional de los derechos humanos. Normativa, jurisprudencia y doctrina de los sistemas Universal e Interamericano. Bogotá: Oficina en Colombia del Alto Comisionado de las Naciones Unidas para los Derechos Humanos.

ONU (Organización de las Naciones Unidas), Asamblea General (1985). Resolución 40/34 de noviembre de 1985.

Parra, J. (2006). Manual de derecho probatorio. Bogotá: Librería Ediciones del Profesional.

RAE (Real Academia Española) (2017a). Contexto. En Diccionario de la lengua española. Recuperado de http://dle.rae.es/?id=AVBbFZW

RAE (Real Academia Española) (2017b). Indicio. En Diccionario de la lengua española. Recuperado de http://dle.rae.es/?id=LOBECME

Revelo, F. y Valbuena, J. (2017). El Decreto 1382 de 2000 por el cual se fijan reglas de reparto en materia de tutela. Un conflicto vigente entre las altas cortes colombianas. Revista Iusta, 2(47), 59-85. Doi: http://dx.doi.org/10.15332/s1900-0448.2017.0047.03

Santa, J. J. (2016). Justicia transicional y fin del conflicto. De la barbarie a la civilidad. Medellín: Librería Jurídica Sánchez R.

Vargas, S. (2018). La fuerza vinculante de la jurisprudencia del Consejo de Estado. Revista Iusta, 1(48), 119-144. Doi: https://doi.org/10.15332/s1900-0448.2018.0048.05

Yani, J. (2017). Amnistía y proporcionalidad desde el punto de vista del Estatuto de Roma en el marco jurídico para la paz en Colombia. Revista Iusta, 2(47), 35-57. Doi: http:// dx.doi.org/10.15332/s1900-0448.2017.0047.02 